\title{
Using Anchoring Vignettes in the Evaluation of Breast Cancer Survivors' Quality of Life
}

\author{
Andreas Hinz \\ Department of Medical Psychology and Medical Sociology, University of Leipzig, Leipzig, Germany
}

\section{Keywords}

Anchoring vignettes - Breast cancer - Quality of life . Response shift · Survivorship

\section{Summary}

Background: Breast cancer survivors often rate their general health as good even though they experience detriments in functioning and multiple symptoms. The hypothesis of this study is that breast cancer survivors changed their frames of reference for evaluating their own health. Methods: A sample of 308 breast cancer survivors were asked to assess their state of health on a 0-100 scale. In addition, 2 vignettes (fictional persons suffering from various health complaints) were designed. The cancer survivors were asked to assess the health of the characters in these vignettes as well. A sample of the general population ( $n=639$ ) served as controls. Results: There were only marginal differences between the cancer survivors ( $M=65.8$ ) and the controls ( $\mathrm{M}=65.5$ ) in how they assessed their own state of health. However, the cancer survivors rated the vignette character with physical problems as being significantly healthier compared to the general population (effect size: $d=0.55)$. The group differences in the assessment of the vignette character with mental problems was markedly lower $(d=0.12)$. Conclusions: It is not sufficient to assess the general self-assessed health state of cancer survivors. Anchoring vignettes are a promising tool for use in correcting for response shift effects.

(c) 2017 S. Karger GmbH, Freiburg

\section{Introduction}

Due to improved screening and treatment, the 5-year breast cancer survival rate has increased markedly over the past few decades [1]. This results in a growing number of breast cancer survivors [2]. Breast cancer survivors' quality of life (QoL) has been intensively investigated in multiple studies [3]. Many investigations reported rather good QoL, while other studies detected detriments in QoL. A close inspection of the results reveals that detriments mainly occur in the physical dimensions of QoL and in several specific symptom areas, including sexual functioning, while mental health is less affected. A recent study [4] examined 6,949 women with breast cancer. Immediately after diagnosis patients' depressive symptoms increased and mental health decreased, but in long-term survivors who had been diagnosed at least 5 years previously, the depression scores decreased and reached the pre-cancer scores. In contrast, physical functioning did not return to pre-cancer levels. Another study with breast cancer survivor [5] examined emotional well-being 9 months after diagnosis and 4 years later. While $25 \%$ experienced a clinically significant decline, $36 \%$ experienced a clinically significant improvement in emotional well-being. Measured with the QoL questionnaire of the European Organisation for Research and Treatment of Cancer (EORTC) QLQ-C30 [6], several studies [7-10] found that the cancer survivors' mean scores for this global health/QoL scale were nearly identical with those of the general population, while on all functioning and symptom scales the cancer survivors reported worse QoL.

One possible explanation for this effect is that response shift effects could have taken place, and that this effect works differently, depending on the nature of the variables to be assessed. Response shift means that people change their frames of reference in the assessment of health $[11,12]$. Such effects have also been detected in breast cancer patients $[13,14]$. The most frequently used techniques to detect and quantify response shift effects are the then-test method and structural equation modeling. A prerequisite for these 2 methods is the presence of 2 measurement points. A further way to investigate such effects of response shift with only 1 measurement point is to use

\section{KARGER}

(c) 2017 S. Karger GmbH, Freiburg

Fax +497614520714
Prof. Dr. Andreas Hinz

Department of Medical Psychology and Medical Sociology University of Leipzig

Philipp-Rosenthal-Str. 55, 04103 Leipzig, Germany

Andreas.Hinz@medizin.uni-leipzig.de 
anchoring vignettes. Vignettes are short descriptions of persons with regard to certain features, e.g. health [15]. If there is indeed a change in participants' frames of reference, this change should not only be detectable in their assessments of themselves but also in their assessments of others, e.g. anchoring vignettes. Anchoring vignettes have been applied extensively in epidemiological research comparing health assessments of general population samples in different countries [16]. In the literature, most anchoring vignettes were described in terms of a single dimension, e.g. physical capacity [17], alcohol consumption [18], or symptoms of urinary dysfunction [19]. Studies with assessments of more complex vignettes comprising several aspects of health are rare. A recent study [20] investigated assessments of rather complex vignettes. People from the general population were asked to evaluate the general health state of the characters represented in these vignettes. The mean scores of this study can be used to compare the assessments that breast cancer survivors made of such vignettes. The hypothesis is that cancer survivors would evaluate the health state of the vignettes as being better than would members of the general population because their frames of reference for making such evaluations had been changed by their experience of cancer. A second hypothesis, also derived from the hypothesis of response shift, is that those cancer survivors who are in a rather bad health situation would assess the characters in these vignettes as being in better health than would cancer survivors in a good health state. This should result in a negative correlation between the assessment of their own health and that of the vignette characters.

In addition to testing these 2 hypotheses, we intended to investigate the relationship between the vignettes' health assessments and sociodemographic, clinical, and psychological factors such as age, education, time since diagnosis, distress, and habitual optimism. Finally, since most vignette studies are cross-sectional, and knowledge of the temporal stability of assessments of vignettes is very limited, we performed a study with 2 measurement points to estimate the stability of the findings.

The aims of the present study were (1) to analyze self-reported health of breast cancer survivors, compared with the general population, (2) to compare survivors' assessments of the vignettes with those given by the general population, and (3) to explore prognostic factors for the assessments of the vignettes.

\section{Methods}

\section{Study Participants}

Study participants were women who took part in a routine post-breast cancer radiological follow-up examination in Germany. Time elapsed since initial cancer diagnosis was at least 6 months. Women who attended the radiological clinic and who had been diagnosed with breast cancer $(n=358)$ were eligible for the study. Informed consent was obtained from the study participants after having explained the aims and the content of the study. The first (t1) examination was performed during or immediately after the radiological examination. 3 months later the women were sent a letter with a return envelope and the $\mathrm{t} 2$ questionnaire, containing the same questions as the 11 questionnaire. The study was approved by the Ethics Committee of the Leipzig University and thus meets the standards of the Declaration of Helsinki in its revised version of 1975 and its amendments of 1983, 1989, and 1996.

\section{General Population}

The reference data were taken from a recent German general population study [20] that included 2,409 males and females with an age range of 18-92 years. The participants of this survey assessed themselves and the vignettes with the same 0-100 scale as the breast cancer patients did. This was a cross-sectional study, not including a retest. From this sample we selected a subsample of women so that the mean age was nearly equal to that of the cancer survivors (66.1 years). The resulting sample of the general population comprised $n=639$ women with a mean age of 66.3 years (standard deviation (SD) 9.4 years).

\section{Instruments}

The respondents were asked to assess their present health on a 0-100 scale according to the Visual Analogue Scale of the QoL questionnaire EQ-5D [21]. The end points of this scale are labeled as worst possible health (0) and best imaginable health (100). The total EQ-5D was not used. In addition, 2 vignettes of patients were described according to the description published in [20]: ' $\mathrm{Pa}$ tient $\mathrm{A}$ is disabled in his mobility due to a disease. He has problems using stairs, cannot perform his daily tasks (e.g. shopping) and occasionally has to use a wheel chair. He has hip and knee pain but considers it tolerable. Mentally he feels well. He is not anxious or depressed and does not see a reason to complain about his health.' 'Patient B has chronic back pain and physicians have been unable to figure out why. Although Patient B can move and fulfil his daily activities without help, he feels alienated by his pain, he mistrusts the physicians, and he perceives his future health situation as hopeless.' The concept behind the design of these 2 vignettes was that for both vignettes information on physical and mental health is given, and that vignette $\mathrm{A}$ is mainly characterized by physical health problems, while for vignette B mental health problems prevail.

Study participants (cancer survivors as well as participants of the general population study) were asked to assess their own health state and the health states of the people described in these 2 vignettes on the same $0-100$ scale. The breast cancer survivors also filled in 2 other questionnaires [22]: the Patient Health Questionnaire-4 (PHQ-4) measuring anxiety and depression with only 4 items, and the Life Orientation Test-Revised (LOT-R) [23], a 10-item instrument measuring habitual optimism and pessimism. We only used the total scores of the PHQ-4 and the LOT-R in the analyses. In addition, the participants were asked to rate their current level of distress with the Distress Thermometer (DT) [24] ranging from 0 (no distress) to 10 (maximum distress).

\section{Statistical Analyses}

Pearson correlations were used to describe the associations between the health assessments. Effect sizes $(d)$ were calculated according to Cohen to indicate the mean score difference between 2 groups, adjusted for the pooled standard deviation. Mean score differences between groups were tested with t-tests. All statistical tests were performed with SPSS version 20.

\section{Results}

\section{Sociodemographic and Clinical Characteristics}

Of the 358 women who were asked to take part in the study, 338 (94.4\%) were willing to participate and filled in the $\mathrm{t} 1$ questionnaire. After 3 months, 308 (91\% of the 338 women) sent the $t 2$ questionnaire back. The following analyses are restricted to those women who took part both at $\mathrm{t} 1$ and $\mathrm{t} 2$. The mean age of the women was 66.1 years ( $\mathrm{SD}=9.6$ years). Table 1 shows further characteristics of the cancer survivors' sample and the corresponding relevant percentages of the general population.

\section{Mean Scores of Participants' Self-Assessments and Their Assessments of the Vignettes}

Table 2 presents mean scores of the cancer survivors' assessments of their own current health and of the 2 vignettes at $t 1$ 
and $\mathrm{t} 2$, together with the corresponding mean scores of the general population. First, we compared the patients' $t 1$ values with those of the general population. The mean health self-assessments of the 2 groups were nearly identical (65.8 and 65.5, respectively; effect size $d=0.02$ ). However, in the assessments of the vignettes there were great differences between cancer survivors and the general population, especially for vignette $A$, which was mainly characterized by physical problems $(d=0.55)$. Cancer survivors rated their own health as being only 12.8 points better than that of vignette A (cf. table 2). This difference was much higher (22.7 points) in the general population. The $t 2$ mean scores of the cancer survivors were nearly identical with the $\mathrm{t} 1$ values (table 2 )

Table 1. Sociodemographic characteristics of the study sample $(\mathrm{n}=308)$ and general population

Table 2. Mean scores and effect sizes of the health assessments

\begin{tabular}{|c|c|c|c|}
\hline & $\mathrm{n}$ & $\%$ & $\mathrm{GP}, \%$ \\
\hline \multicolumn{4}{|l|}{ Age } \\
\hline$\leq 59$ years & 68 & 22.1 & 25.5 \\
\hline $60-69$ years & 107 & 34.7 & 32.5 \\
\hline$\geq 70$ years & 133 & 43.2 & 41.9 \\
\hline \multicolumn{4}{|l|}{ Civil status } \\
\hline $\begin{array}{l}\text { Living without } \\
\text { partner }\end{array}$ & 105 & 34.1 & \\
\hline Living with partner & 202 & 65.6 & 53 \\
\hline n.a. & 1 & 0.3 & \\
\hline \multicolumn{4}{|l|}{ Education } \\
\hline$\leq 9$ years & 89 & 28.9 & 43.7 \\
\hline $10-11$ years & 146 & 47.4 & 36.5 \\
\hline$\geq 12$ years & 71 & 23.1 & 19.8 \\
\hline n.a. & 2 & 0.6 & \\
\hline \multicolumn{4}{|l|}{ Time since diagnosis } \\
\hline$\leq 5$ years & 165 & 53.6 & \\
\hline$>5$ years & 143 & 46.4 & \\
\hline \multicolumn{4}{|l|}{ Chemotherapy } \\
\hline No & 157 & 51.0 & \\
\hline Yes & 151 & 49.0 & \\
\hline \multicolumn{4}{|l|}{ Radiotherapy } \\
\hline No & 50 & 16.2 & \\
\hline Yes & 258 & 83.8 & \\
\hline \multicolumn{4}{|l|}{ Hormone therapy } \\
\hline No & 143 & 46.4 & \\
\hline Yes & 158 & 51.3 & \\
\hline n.a. & 7 & 2.3 & \\
\hline
\end{tabular}

$\mathrm{GP}=$ general population, n.a. = not available
Self-assessment of health state is positively associated with assessments of the vignette characters' health states (table 3 ). Both vignettes are only marginally associated $(r=0.04$ at $\mathrm{t} 1$ and $r=0.12$ at $\mathrm{t} 2$ ).

\section{Temporal Stability}

The following correlations between the $\mathrm{t} 1$ and the $\mathrm{t} 2$ scores were obtained: Own health: $r=0.66$; Vignette A: $r=0.43$; Vignette B: $r=0.43$; Difference score Own health minus Vignette A: $r=0.49$; Difference score Own health minus Vignette B: $r=0.52$. All these coefficients were statistically significant $(\mathrm{p}<0.001)$.

\section{Correlations with other Mental Health Variables}

The self-assessments of health state and the difference scores (personal health state minus assessment of vignettes) were significantly correlated with distress, habitual optimism (LOT) and anxiety and depression (PHQ-4) (table 4). The highest correlation was found for the relationship between self-assessed health and the PHQ- 4 scores ( $r=-0.50$ and $r=-0.57$ at $\mathrm{t} 1$ and $\mathrm{t} 2$, respectively). Distressed people rated their health state relative to the vignettes as being less healthy than people who were not distressed ( $r$ between -0.19 and -0.35 ).

Age, education and time since diagnosis were only marginally correlated with the cancer survivors' self-assessed health and with their ratings of the vignette characters' health (table 5).

\section{Discussion}

Breast cancer survivors rate their own global state of health as being good; there was nearly no difference between their self-assessments and those of women from the general population. This seems

Table 3. Correlations between health assessments

\begin{tabular}{llll}
\hline & Own health & Health Vig. A & Health Vig. B \\
\hline Own health & - & $0.34^{\star *}$ & $0.17^{* *}$ \\
Health Vig. A & $0.21^{* *}$ & - & 0.04 \\
Health Vig. B & $0.14^{*}$ & $0.12^{\star}$ & -
\end{tabular}

Upper right triangle: $\mathrm{t} 1$ correlations; lower left triangle: $\mathrm{t} 2$ correlations. Health Vig. A/B = health assessment of vignette $\mathrm{A} / \mathrm{B}$. ${ }^{* *} \mathrm{p}<0.01,{ }^{*} \mathrm{p}<0.05$

\begin{tabular}{|c|c|c|c|c|c|c|c|}
\hline & \multirow[t]{2}{*}{$\mathrm{t} 1, \mathrm{M}(\mathrm{SD})$} & \multirow[t]{2}{*}{$\mathrm{t} 2, \mathrm{M}(\mathrm{SD})$} & \multirow[t]{2}{*}{$\mathrm{GP}, \mathrm{M}(\mathrm{SD})$} & \multicolumn{2}{|c|}{$\mathrm{t} 1-\mathrm{GP}$} & \multicolumn{2}{|c|}{ t2-GP } \\
\hline & & & & $d$ & Sig. & $d$ & Sig. \\
\hline Own health & $65.8(18.6)$ & $65.5(18.6)$ & $65.5(20.2)$ & 0.02 & ns & 0.00 & ns \\
\hline Vig. A & $53.0(18.7)$ & $53.8(18.3)$ & $42.8(18.3)$ & 0.55 & $<0.001$ & 0.60 & $<0.001$ \\
\hline Vig. B & $46.9(19.4)$ & $46.8(18.7)$ & $44.7(17.3)$ & 0.12 & ns & 0.12 & ns \\
\hline Own health - Vig. A & $12.8(21.4)$ & $11.7(23.1)$ & $22.8(24.5)$ & 0.44 & $<0.001$ & 0.47 & $<0.001$ \\
\hline Own health - Vig. B & $18.9(24.5)$ & $18.7(24.5)$ & $20.9(25.1)$ & 0.08 & ns & 0.09 & ns \\
\hline
\end{tabular}

$\mathrm{t} 1 / 2=$ first/second questionaire, $\mathrm{GP}=$ general population, $\mathrm{M}=$ mean, $d=$ effect size, Sig. = significance, $\mathrm{Vig} .=$ vignette, ns = not significant 
Table 4. Correlations between health assessments and other scales

Table 5. Correlations between health assessments, age, education, and time since diagnosis

\begin{tabular}{|c|c|c|c|c|c|c|}
\hline & \multicolumn{3}{|l|}{$\mathrm{t} 1$} & \multicolumn{3}{|l|}{$\mathrm{t} 2$} \\
\hline & Distress & LOT-R & PHQ-4 & Distress & LOT-R & PHQ-4 \\
\hline Own health & $-0.44^{* *}$ & $0.31^{* *}$ & $-0.50^{* *}$ & $-0.52^{* *}$ & $0.39^{* *}$ & $-0.57^{\star *}$ \\
\hline Vig. A & $-0.21^{* *}$ & 0.10 & $-0.15^{\star *}$ & $-0.23^{* *}$ & $0.12^{\star}$ & $-0.15^{\star *}$ \\
\hline Vig. B & $-0.15^{\star \star}$ & 0.03 & -0.06 & -0.06 & 0.00 & 0.00 \\
\hline Own health - Vig. A & $-0.19^{* *}$ & $0.18^{* *}$ & $-0.30^{* *}$ & $-0.23^{* *}$ & $0.22^{* *}$ & $-0.34^{* *}$ \\
\hline Own health - Vig. B & $-0.21^{* *}$ & $0.22^{* *}$ & $-0.34^{* *}$ & $-0.35^{* *}$ & $0.30^{* *}$ & $-0.44^{* *}$ \\
\hline
\end{tabular}

$\mathrm{t} 1 / 2=$ first/second questionaire, LOT-R = Life Orientation Test-Revised, PHQ-4 = Patient Health Questionnaire- 4 , Vig. = vignette.

${ }^{* *} \mathrm{p}<0.01,{ }^{*} \mathrm{p}<0.05$.

\begin{tabular}{|c|c|c|c|c|c|c|}
\hline & \multicolumn{3}{|l|}{$\mathrm{t} 1$} & \multicolumn{3}{|l|}{$\mathrm{t} 2$} \\
\hline & Age & Education & $\begin{array}{l}\text { Time since } \\
\text { diagnosis }\end{array}$ & Age & Education & $\begin{array}{l}\text { Time since } \\
\text { diagnosis }\end{array}$ \\
\hline Own health & -0.01 & 0.04 & -0.05 & -0.07 & -0.00 & -0.08 \\
\hline Vig. A & -0.02 & $0.13^{*}$ & -0.08 & -0.04 & 0.01 & -0.04 \\
\hline Vig. B & 0.03 & $-0.11^{\star}$ & -0.08 & 0.08 & $-0.12^{*}$ & -0.05 \\
\hline \multicolumn{7}{|l|}{ Difference } \\
\hline Own health - vig. A & 0.00 & -0.08 & 0.02 & -0.03 & -0.01 & -0.03 \\
\hline Own health - vig. B & -0.03 & $0.12^{\star}$ & 0.02 & $-0.11^{\star}$ & 0.09 & -0.02 \\
\hline
\end{tabular}

$\mathrm{t} 1 / 2=$ first/second questionaire, $\mathrm{Vig} .=$ vignette

${ }^{*} \mathrm{p}<0.05$. to contradict previous findings that reported detriments in healthrelated QoL in both breast cancer patients and survivors. However, we only investigated the overall health assessments, and previous research also confirmed that in terms of these overall assessments there were only small differences between these groups [10,25]. This does not at all mean that these groups were equal with regard to specific symptoms or restrictions in functioning or body image [26].

According to our first hypothesis, cancer survivors assess the vignette characters as being markedly healthier, compared with the assessment of the general population. A straightforward explanation is that they adapted their internal standards as a result of their own disease experience. Possible theoretical explanations for such adaptation processes are social downward comparisons, set-point theory, and cognitive mechanisms in adaptation-level theory. In our study we cannot distinguish between these explanations. The difference between the cancer survivors and the general population is greatest in the assessment of vignette $\mathrm{A}$, which is mainly characterized by physical problems (difference $=10.2$, effect size $d=0.55$ ), while the difference was small for vignette $B$, which is characterized by mental problems (difference $=2.2$, effect size $d=0.08$ ) at $\mathrm{t} 1$. Therefore, complex vignettes, especially those indicating physical impairments, seem to be promising tools for exploring changes in the frame of reference in global health assessments. The mean scores of the $\mathrm{t} 1$ and the $\mathrm{t} 2$ examination were very similar, indicating stability and generalizability of the mean scores.

The second hypothesis was that correlations between participants' self-assessed health and their assessments of the vignette characters' health were negative. However, we found positive cor- relations. Other studies $[16,20]$ also found such positive associations. Obviously, a judgment effect is stronger than the hypothesized response shift effect. This judgment effect means that people differ in their preferred use of response scales. While some people tend to give positive judgments, irrespective of the content, other people tend to the negative side, which results in a positive correlation of the judgments. This effect is associated with the 'yes-set' effect or acquisition effect [27], indicating the tendency of people to give affirmative answers.

It is not surprising that self-reported health was negatively associated with distress, anxiety, depression, and lack of optimism. The assessments of the vignette characters' health were also negatively associated with distress and (at least at t1) anxiety and depression, meaning that the judgment effect was stronger than the response shift effect in our sample.

Age, educational level and time since diagnosis were not associated with participants' assessments of their own health, and, more importantly in the context of this study, with their assessments of the health of the characters in the vignettes. By contrast, a recent study [28] found that well-educated people tended to evaluate vignettes' health states as slightly more negative than less-well-educated people.

Vignettes can be assessed in different ways. We used the 0-100 scale adopted from the EQ-5D for rating health. In other studies self-rated health is often assessed with 5 categories: very poor, poor, neither good nor poor, good, very good [29]; poor, fair, good, very good, excellent [30]; or poor, sometimes good/poor, fair, good, very good [31]. Due to these differences the results of these 
5-point answer studies are not directly comparable and require sophisticated nonparametric statistics. The 0-100 scale avoids these problems and seems to be a good alternative.

Some limitations should be mentioned. The study was conducted with breast cancer survivors. As such, the generalizability to other kinds of cancer is unclear. Health state was assessed with a single item. Questionnaires with more items are generally more reliable. However, single-items measurements also provide reliable information [32]. Although the control group matched the cancer survivors' group well in terms of gender and age, there were differences concerning marital status (partnership) and education. The vignettes designed for this study might have been too restricted in their QoL. A greater number of vignettes (and averaging across the judgments) could have provided a better basis for the estimation of the response shift effect. Since we did not obtain an objective measure of health we can only draw conclusions about self-reported health. It would be interesting to investigate the relationship between objective health and the assessment of the vignettes. However, the comparison between the 2 groups, breast cancer survivors and general population, was based on objective criteria.
In conclusion, anchoring vignettes can be used to identify changes in frame of reference for a certain group of patients or cancer survivors on the level of mean scores. Clinical oncologists should be aware that relatively good self-reported health mean scores are, at least in part, due to changes in the frames of reference. Therefore, these scores do not indicate the absence of supportive care needs.

\section{Acknowledgments}

This study was supported by the Deutsche Forschungsgemeinschaft DFG (HI 1108/5-1 AO 611770). The author thanks Dr. Kerstin Fuhrmann for her support in collecting the data.

\section{Disclosure Statement}

The author declares that he has no conflict of interest.

\section{References}

1 Surveillance, Epidemiology, and End Results (SEER): 5-Year Relative and Period Survival by Year of Diagnosis. Bethesda, MD, National Cancer Institute, 2013. http://seer.cancer.gov/csr (accessed 10 July 2016).

2 Siegel R, DeSantis C, Virgo K, et al.: Cancer treatment and survivorship statistics, 2012. CA Cancer J Clin 2012;62:220-241.

3 Mols F, Vingerhoets AJ, Coebergh JW, van de PollFranse LV: Quality of life among long-term breast cancer survivors: A systematic review. Eur J Cancer 2005; 41:2613-2619.

4 Jones SM, LaCroix AZ, Li W, et al.: Depression and quality of life before and after breast cancer diagnosis in older women from the Women's Health Initiative. Cancer Surviv 2015;9:620-629.

5 Janz NK, Friese CR, Li Y, et al.: Emotional well-being years post-treatment for breast cancer: Prospective, multi-ethnic, and population-based analysis. J Cancer Surviv 2014;8:131-142.

6 Aaronson NK, Ahmedzai S, Bergman B, et al.: The European Organization for Research and Treatment of Cancer QLQ-C30 - A quality-of-life instrument for use in international clinical trials in oncology. J Natl Cancer Inst 1993;85:365-376.

7 Chu W, Dialla PO, Roignot P, et al.: Determinants of quality of life among long-term breast cancer survivors. Qual Life Res 2016;25:1981-1990.

8 Arndt V, Merx H, Stegmaier C, et al.: Quality of life in patients with colorectal cancer 1 year after diagnosis compared with the general population: A populationbased study. J Clin Oncol 2004;22:4829-4836.

9 Arndt V, Merx H, Stegmaier C, et al.: Persistence of restrictions in quality of life from the first to the third year after diagnosis in women with breast cancer. J Clin Oncol 2005;23:4945-4953.

10 Hinz A, Mehnert A, Degi C, et al.: The relationship between global and specific components of quality of life, assessed with the EORTC QLQ-C30 in a sample of 2019 cancer patients. Eur J Cancer Care 2016; doi $10.1111 /$ ecc. 12416
11 Schwartz CE, Bode R, Repucci N, et al.: The clinical significance of adaptation to changing health: A metaanalysis of response shift. Qual Life Res 2006;15:15331550

12 Sprangers MAG, Schwartz CE: Integrating response shift into health-related quality of life research: A theoretical model. Soc Sci Med 1999;48:1507-1515.

13 Hamidou Z, Dabakuyo-Yonli TS, Guillemin F, et al. Impact of response shift on time to deterioration in quality of life scores in breast cancer patients. PLoS One 2014;9:e96848.

14 Dabakuyo TS, Guillemin F, Conroy T, et al.: Response shift effects on measuring post-operative quality of life among breast cancer patients: A multicenter cohort study. Qual Life Res 2013;22:1-11.

15 Grol-Prokopczyk H, Verdes-Tennant E, McEniry M, Ispany M: Promises and pitfalls of anchoring vignettes in health survey research. Demography 2015;52:17031728.

16 Angelini V, Cavapozzi D, Corazzini L, Paccagnella O: Do Danes and Italians rate life satisfaction in the same way? Using vignettes to correct for individual-specific scale biases. Oxford Bull Econom Stat 2014;76:643666.

17 Salomon JA, Tandon A, Murray CJL: Comparability of self-rated health: Cross sectional multi-country survey using anchoring vignettes. Br Med J 2004;328:258-261.

18 van Soest A, Delaney L, Harmon C, et al.: Validating the use of anchoring vignettes for the correction of response scale differences in subjective questions. J $\mathrm{R}$ Stat Soc Ser A Stat Soc 2011;174:575-595.

19 Korfage IJ, Koning HJ de, Essink-Bot ML: Response shift due to diagnosis and primary treatment of localized prostate cancer: A then-test and a vignette study. Qual Life Res 2007;16:1627-1534

20 Hinz A, Häuser W, Glaesmer H, Brähler E: The relationship between perceived own health state and health assessments of anchoring vignettes. Int J Clin Health Psychol 2016;16:128-136.

21 Brooks R: EuroQol: The current state of play. Health Policy 1996;37:53-72.
22 Löwe B, Wahl I, Rose M, et al: A 4-item measure of depression and anxiety: Validation and standardization of the Patient Health Questionnaire-4 (PHQ-4) in the general population. J Affect Disord 2010;122:86-95.

23 Scheier MF, Carver CS, Bridges MW: Distinguishing optimism from neuroticism (and trait anxiety, self-mastery, and self-esteem) - A reevaluation of the Life Orientation Test. J Pers Soc Psychol 1994;67:1063-1078.

24 Donovan KA, Grassi L, McGinty HL, Jacobsen PB Validation of the distress thermometer worldwide: state of the science. Psychooncology 2014;23:241-250.

25 Koch L, Jansen L, Herrmann A, et al.: Quality of life in long-term breast cancer survivors - a 10-year longitudinal population-based study. Acta Oncol 2013;52: 1119-1128.

26 Spatuzzi R, Vespa A, Lorenzi P, et al.: Evaluation of social support, quality of life, and body image in women with breast cancer. Breast Care 2016;11:28-32.

27 Ferrando PJ, Lorenzo-Seva U: Acquiescence as a source of bias and model and person misfit: A theoretical and empirical analysis. Br J Math Stat Psychol 2010; 63:427-448.

28 Hanandita W, Tampubolon G: Does reporting behaviour bias the measurement of social inequalities in selfrated health in Indonesia? An anchoring vignette analysis. Qual Life Res 2016;25:1137-1149.

29 Crane M, Rissel C, Greaves S, Gebel K: Correcting bias in self-rated quality of life: An application of anchoring vignettes and ordinal regression models to better understand QoL differences across commuting modes. Qual Life Res 2016;25:257-266.

30 Grol-Prokopczyk H, Freese J, Hauser RM: Using anchoring vignettes to assess group differences in general self-rated health. J Health Soc Behav 2011;52:246-261.

31 Galenkamp H, Deeg DJH, Braam AW, Huisman M: 'How was your health 3 years ago?' Predicting mortality in older adults using a retrospective change measure of self-rated health. Geriat Gerontol Int 2013;13:678-686.

32 Bowling A: Just one question: If one question works, why ask several? J Epidemiol Community Health 2005; 59:342-345. 